\title{
ANÁLISE DA ADERÊNCIA DOS PILARES DA INDÚSTRIA 4.0 PARA OS PROFISSIONAIS DA ENGENHARIA DE PRODUÇÃO
}

Carlos Roberto Franzini Filho - crfilho@anhembi.br

Departamento de Engenharia de Produção

Universidade Anhembi Morumbi, Rua Casa do Ator, 275, Vila Olímpia

04546-001 - São Paulo - SP

Lucas Santana Spinelli-lucas.striker9@hotmail.com

Departamento de Engenharia de Produção

Universidade Anhembi Morumbi, Rua Casa do Ator, 275, Vila Olímpia

04546-001 - São Paulo - SP

Resumo: Os profissionais que atuam na Engenheira de Produção são capazes de atuar em diversas áreas dentro de uma organização e assumem responsabilidades no gerenciamento de materiais, financeiros e humanos. Para um profissional que almeja construir uma carreia de sucesso dentro da Engenharia, é importante que alguns fatores sejam levados em consideração e buscados pelos engenheiros, como por exemplo, a atualização profissional. Dentro desta abordagem, a indústria 4.0 conhecida também como a Quarta Revolução Industrial é um conceito de indústria proposto recentemente que abrange as principais inovações tecnológica aplicadas aos processos de manufatura e prestação de serviços. Dentro desta abordagem, o objetivo deste trabalho é analisar a aderência dos pilares da indústria 4.0 para os profissionais da Engenharia de Produção. Para atingir ao objetivo proposto, foi realizada uma survey exploratória junto aos profissionais da Engenharia de Produção. Os resultados apontam para os pilares da indústria 4.0 com maior e menor aderência entre os profissionais da Engenharia de Produção. Espera-se que os resultados alcançados a partir da realização deste trabalho possam nortear futuros trabalhos, bem como sugerir os pilares que carecem de maior dedicação quanto a atualização dos profissionais de Engenharia de Produção.

Palavras-chave: Engenharia de Produção. Indústria 4.0. Quarta Revolução Industrial. 


\section{INTRODUÇÃO}

No Brasil, os cursos de Engenharia tiveram o seu início em meados do século XX, na Escola Politécnica da USP e atualmente, de acordo com o último Censo de Educação Superior no Brasil, a educação encontra-se em processo de crescimento acelerado e possui um elevado número de instituições de ensino em engenharia (OLIVEIRA, 2005).

Conceber as competências necessárias para a formação de um engenheiro de produção é uma preocupação tanto das empresas quanto das universidades que são responsáveis por suprir a necessidade de profissionais qualificados, pois a busca por diferenciais competitivos de qualidade e produtividade no mercado de trabalho é elevada. Atualmente acrescenta-se à estas competências necessárias as questões que envolvem a Indústria 4.0 e seus pilares.

A indústria 4.0 conhecida também como a Quarta Revolução Industrial é um conceito de indústria proposto recentemente que abrange as principais inovações tecnológica aplicadas aos processos de manufatura e prestação de serviços. Os impactos da Indústria 4.0 sobre a produtividade, a redução de custos, o controle sobre o processo produtivo, a customização da produção, dentre outros, apontam para uma transformação profunda nas plantas fabris. Os pilares da indústria 4.0 são:

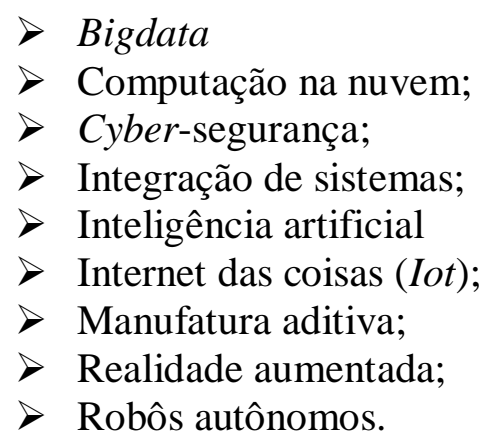

No Brasil, a participação da indústria de transformação no PIB, que já havia atingido mais de $20 \%$ em meados da década de 1980 , reduziu-se para próximo de $11 \%$, fruto de mudanças na estrutura produtiva do país e dos novos modelos de negócios trazidos pela disrupção tecnológica (CNI, 2016).

A Engenharia de Produção tem a finalidade de desenvolver profissionais responsáveis por todos os processos produtivos dentro de uma organização. Além da formação o engenheiro de produção tem que estar sempre atualizado com as transformações tecnológicas, aplicação das melhores ferramentas de gestão e atento às transformações e inovações que a área vem sofrendo nos últimos anos (BATALHA, 2008).

Para Franzini Filho (2018), o Engenheiro de Produção é um profissional extremamente versátil e possui notória adaptabilidade e capacidade de interpretar dados e transformá-los em informação de suma importância. Essas capacidades são muito apreciadas no mercado de trabalho, possibilitando uma enorme gama de alternativas para esse engenheiro desenvolver sua carreira. Por outro lado, as consequências em razão da falta destes conhecimentos podem causar são incertas, devido à grande gama de áreas que o Engenheiro de Produção pode atuar. Mas é seguro afirmar que à medida que o tempo passe esses conhecimentos serão mandatórios para a permanência no mercado de trabalho, quem dirá crescimento em determinado mercado ou serviço.

A partir das considerações iniciais, o objetivo deste trabalho é analisar a aderência dos pilares da indústria 4.0 para os profissionais da Engenharia de Produção. A relevância em estudar este fenômeno se dá por diversos fatores: mercado de trabalho para o Engenheiro de 
Produção e Engenharias em geral, as transformações que os mercados e serviços sofrerão pela indústria 4.0, impactos ambientais e sociais e muitos outros.

\section{REFERENCIAL TEÓRICO}

Anteriormente ao surgimento da indústria, a produção era toda artesanal, o que propiciava pequenas produções e que não interessava ao regime capitalista. A Primeira Revolução Industrial (Indústria 1.0) surgiu na Inglaterra entre os anos de 1760 e 1860 e se estendeu para outros países como: Alemanha, Bélgica, Estados Unidos, França, Holanda e Rússia. Este período fomentou a capitalismo e ficou marcado por importantes invenções e descobertas, como a utilização do carvão como fonte de energia e a descoberta da máquina a vapor (VENTURELLI, 2017).

A Segunda Revolução Industrial (Indústria 2.0) destacou-se pela busca da maximização dos lucros, especialização do trabalho e ampliação da produção. Neste período, surgiu em 1914 o fordismo com a introdução da primeira linha de montagem automatizada. $\mathrm{O}$ fordismo criado por Henry Ford destacou-se pela produção e consumo em massa. Para Boettcher (2015) foi neste período que países como Alemanha, Estados Unidos, França e Japão tornaram-se líderes globais de tecnologia e houve grande aceleração e crescimento da economia mundial.

A oferta para o curso de Engenharia de Produção foi disponibilizada em resposta às necessidades das empresas em aumentar o nível de operacionalização dos sistemas de produção, após a Revolução Industrial. Com o aumento significativo na competitividade entre empresas, a Engenharia de Produção mostrou sua importância na melhoria da qualidade de processos, (CUNHA, 2002).

A partir das inovações tecnológicas surgidas nos séculos XX e XXI, originou-se a Terceira Revolução Industrial (Indústria 3.0). Destaca-se para este período a utilização de diferentes fontes de energia, utilização de recursos de informática, direitos trabalhistas, consciência ambiental, massificação de produtos tecnológicos e a substituição da mão-de-obra por máquinas mais modernas.

No Brasil observa-se muitas empresas ainda ingressando na Terceira Revolução Industrial e estas mesmas empresas encontram-se em diferentes níveis de desenvolvimento tecnológico segundo Santos (2017). Percebe-se o atraso na substituição das linhas de produção tradicionais por linhas de produção automatizadas quando comparado a países desenvolvidos como Alemanha, Estados Unidos e Japão (HAHN, 2017). A Figura 1 ilustra a evolução das quatro revoluções industriais.

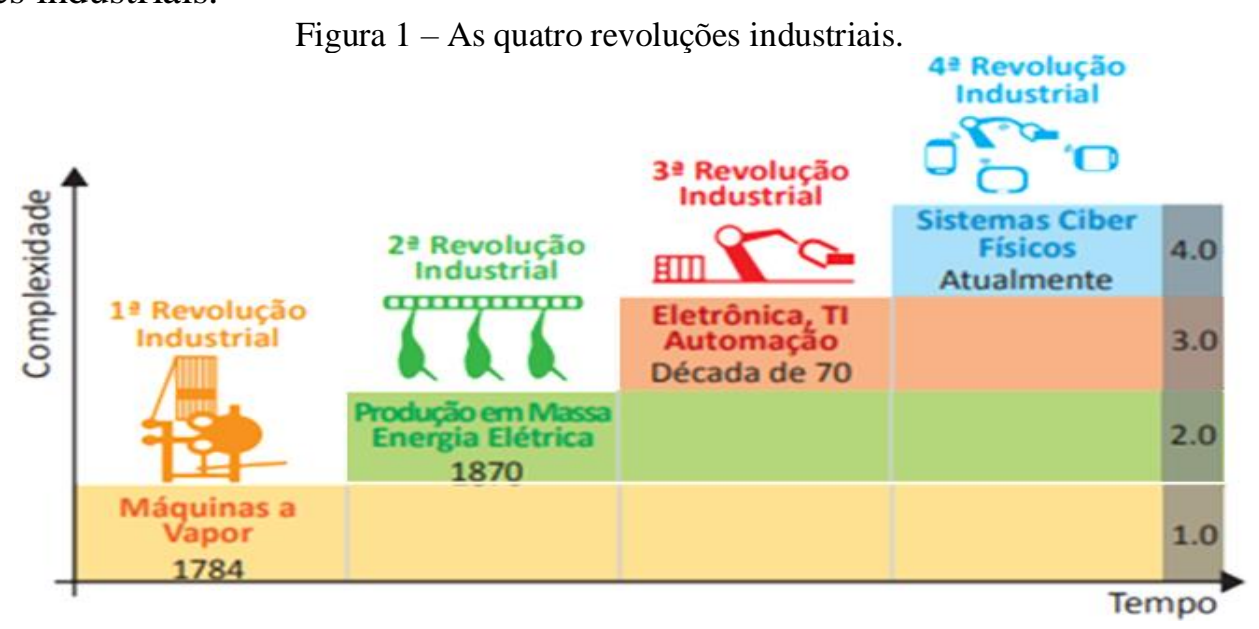

Fonte: Adaptado de Costa (2017). 
Para que as empresas e os profissionais sejam capazes de sobreviver nesta sociedade da informação, elas necessitam ter fácil e rápida adaptação às mudanças e adequar-se as tecnologias que as coloquem continuamente na competição global (Silva, 1999), ou seja, novas habilidades e competências (não técnicas) têm sido exigidas tanto pela sociedade como pelo mercado de trabalho, para que um engenheiro possa exercer sua profissão.

A Indústria 4.0 ou $4^{a}$ Revolução Industrial é a fusão do conjunto de tecnologias da internet com o mundo da manufatura, mundo digital e biológico. Estima-se que este termo foi usado pela primeira vez em 2011, é oriunda de um projeto de estratégias do governo alemão votado para a tecnologia (SILVEIRA, 2017). O Quadro 1 ilustra os pilares da considerados para a indústria 4.0:

Quadro 1 - Pilares da Indústria 4.0.

\begin{tabular}{|c|c|}
\hline $\begin{array}{l}\text { Pilares da } \\
\text { Indústria } \\
\quad 4.0\end{array}$ & Descrição \\
\hline $\begin{array}{l}\text { Big Data } \\
\text { analytics }\end{array}$ & $\begin{array}{l}\text { Entende-se por Big Data como a capacidade de grande armazenamento e análise estatística de } \\
\text { informações geradas por um sistema. Com a estruturação dos dados armazenados é possível } \\
\text { conceber uma estrutura racional. O Big Data também incorpora a análise de dados não } \\
\text { estruturados como imagens, expressões faciais, sons e outros. }\end{array}$ \\
\hline $\begin{array}{l}\text { Computação } \\
\text { em Nuvem }\end{array}$ & $\begin{array}{l}\text { A computação na nuvem ou "cloud computing" (em inglês) consiste no armazenamento e } \\
\text { processamento de dados sem o gerenciamento ativo do usuário. É assim denominada por não } \\
\text { se saber onde os dados armazenados e processados estão localizados. Mais de um servidor } \\
\text { podem estar em lugares distintos e processando de forma conjunta, ou os mesmos dados } \\
\text { gerados por uma determinada empresa, podem estar localizados em diferentes servidores. }\end{array}$ \\
\hline $\begin{array}{c}\text { Cyber } \\
\text { segurança }\end{array}$ & $\begin{array}{l}\text { Em razão da integração de sistemas e a constante troca de informações que ela promove, se } \\
\text { faz necessário a criação de meios para proteger esse ciclo contra invasões e interferências } \\
\text { externas que podem gerar roubo ou danos à integridade dos sistemas. }\end{array}$ \\
\hline $\begin{array}{l}\text { Integração } \\
\text { de } \\
\text { Sistemas }\end{array}$ & $\begin{array}{l}\text { Esse pilar engloba e permite que a indústria } 4.0 \text { opere em sua capacidade plena. Possuindo } \\
\text { todos os sistemas integrados é possível se analisar, explorar e interagir com qualquer parte da } \\
\text { fábrica de qualquer lugar do mundo. Uma barreira enfrentada atualmente é integrar sistemas } \\
\text { de diferentes desenvolvedores, ainda não conversam bem entre si. }\end{array}$ \\
\hline $\begin{array}{l}\text { Inteligência } \\
\text { Artificial } \\
\quad(\mathrm{AI})\end{array}$ & $\begin{array}{l}\text { A Inteligência Artificial (IA) pode ser definida como a ciência e engenharia capaz de extrair a } \\
\text { capacidade das máquinas em simular o pensamento dos seres humanos, obtendo a capacidade } \\
\text { de aprender, raciocinar, perceber, deliberar e decidir de forma racional e inteligente a respeito } \\
\text { de um determinado problema. }\end{array}$ \\
\hline $\begin{array}{l}\text { Internet das } \\
\text { Coisas }(I o T)\end{array}$ & $\begin{array}{l}\text { A internet das coisas ou "internet of things" (Iot) consiste em conectar objetos utilizados } \\
\text { diariamente, como máquinas, veículos, aparelhos eletrodomésticos, à internet, de forma a } \\
\text { serem acessados remotamente, por dispositivos móveis, como smartphones, notebooks, tablets } \\
\text { ou fixos que tenham conexão com a internet. }\end{array}$ \\
\hline $\begin{array}{c}\text { Manufatura } \\
\text { Aditiva }\end{array}$ & $\begin{array}{l}\text { A Manufatura aditiva é uma definição mais abrangente da Impressão 3D. Trata-se da adição } \\
\text { de camadas de materiais diversos para se obter as formas desejadas. Essa tecnologia entrega } \\
\text { praticidade e velocidade na fabricação de peças já onde serão colocadas em uso. }\end{array}$ \\
\hline $\begin{array}{l}\text { Realidade } \\
\text { Aumentada }\end{array}$ & $\begin{array}{l}\text { A Realidade Aumentada permite a interação do mundo real com o virtual e seus elementos, } \\
\text { essa interação permite ampliar a percepção e a extração de informações do ambiente estudado. } \\
\text { Interagindo em tempo real na própria perspectiva 3D, a gama de possibilidades para aplicações } \\
\text { é enorme, dentre elas, simulações de plantas de fábricas inteiras que ainda nem foram criadas, } \\
\text { acessos a informações desse ambiente e como torná-lo mais eficiente e outros. }\end{array}$ \\
\hline
\end{tabular}




\begin{tabular}{|c|l|}
\hline $\begin{array}{c}\text { Robôs } \\
\text { Autônomos }\end{array}$ & $\begin{array}{l}\text { Sem esse pilar não existe indústria 4.0, ele permite a automação e a execução com enorme } \\
\text { precisão e agilidade dos processos produtivos. Nesse aspecto quanto menor interação humana } \\
\text { melhor. Torna possível padrões de produção muito mais altos e uma grande redução de custos. }\end{array}$ \\
\hline
\end{tabular}

Fonte: Adaptado de Sacomano (2018).

Para Sakurai e Zuchi (2018), destaca-se que indústria 4.0 surgiu a partir de um cenário de grandes evoluções tecnológicas e traz em seu contexto projetos de uma indústria do futuro e impactos são notáveis e tendem a mudar significativamente a atual sociedade.

\section{METODOLOGIA}

Para atingir ao objetivo proposto com a realização deste trabalho, aplicou-se uma survey exploratória aos profissionais que atuam dentro da Engenharia de Produção. De acordo com Forza (2002), uma survey exploratória é a pesquisa que envolve a coleta de informações por meio de indivíduos sobre eles mesmos ou sobre as organizações às quais eles pertencem ou consomem.

As respostas foram classificadas conforme escala Likert, sendo: (1) discordo totalmente, (2) discordo parcialmente, (3) indiferente, (4) concordo parcialmente e (5) concordo totalmente (CUNHA et al., 2007). A Figura 2 ilustra a estrutura metodológica considerada para a realização deste trabalho quanto a natureza, abordagem, objetivos, método, técnica de coleta e análise dos dados.

Figura 2 - Estrutura metodológica.

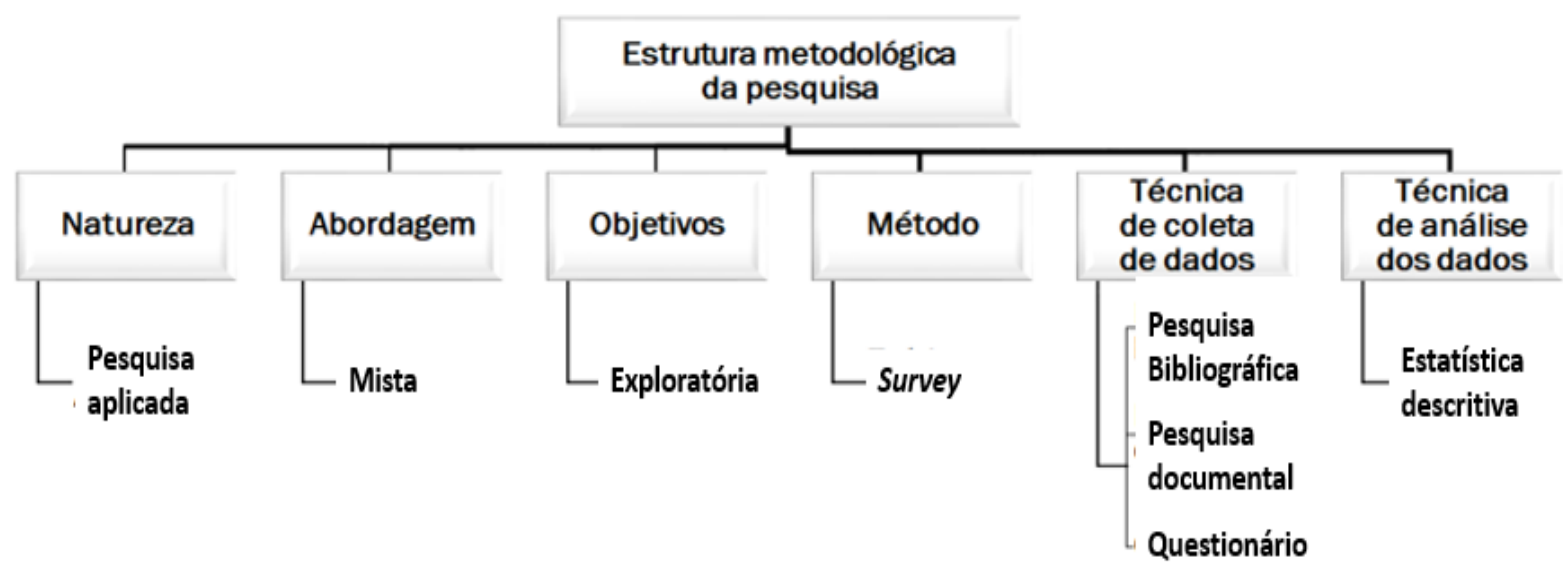

Fonte: Elaborado pelos autores (2020).

- O tamanho da amostra foi estimado em um mínimo de 55 respondentes com um erro máximo de $5 \%$ e confiabilidade de $95 \%$ conforme dados extraídos do aplicativo Survey Monkey.

Considerando o objetivo proposto, ficou estabelecida a seguinte hipótese provável:

$>$ Hipótese 1: existe baixa aderência entre os pilares da indústria 4.0 e os profissionais que atuam na área da Engenharia de Produção.

\section{ANÁLISE \& DISCUSSÃO DOS RESULTADOS}

A survey exploratória foi aplicada nos meses de junho e julho de 2020 e o questionário foi disponibilizado via rede social. Colaboraram com a pesquisa uma amostra de 63 respondentes, 
todos atuantes na área de Engenharia de Produção. A Figura 3 ilustra a caracterização dos respondentes quanto a área de atuação, cargo ocupado e tempo de formado.

O gráfico (a) ilustra a área de atuação dos respondentes, onde observa-se que a maioria $(25,4 \%)$ dos respondentes atuam na área de engenharia de operações e processos de produção seguidos de $12,7 \%$ de áreas diversas e $19 \%$ atuantes nas áreas comercial e financeira. Observase que $18 \%$ dos respondentes atuam nas áreas de administração e marketing. $\mathrm{O}$ restante dos respondentes tem atuado nas áreas de engenharia da qualidade, engenharia do produto, logística, engenharia organizacional e educação.

Sobre os cargos ocupados pelos respondentes ilustrados no gráfico (b), a maioria $(33,3 \%)$ tem atuado como analistas e gerentes (19\%). Observa-se $14,3 \%$ atuam como como coordenadores e supervisores, $10 \%$ como diretores e os demais têm atuado como técnicos, estagiários, assistentes e cargos operacionais.

O tempo de formado dos respondentes está ilustrado no gráfico (c) onde observa-se $38,1 \%$ há mais de 5 anos como formado, 20,6\% há mais de 2 anos como formado, 17,5\% recémformados, 14,3\% graduando atualmente e 9,5\% formados há mais de um ano.

Figura 3 - Caracterização dos respondentes.

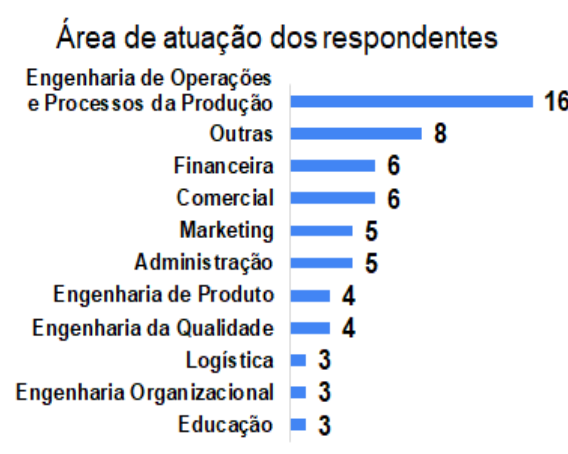

(a)

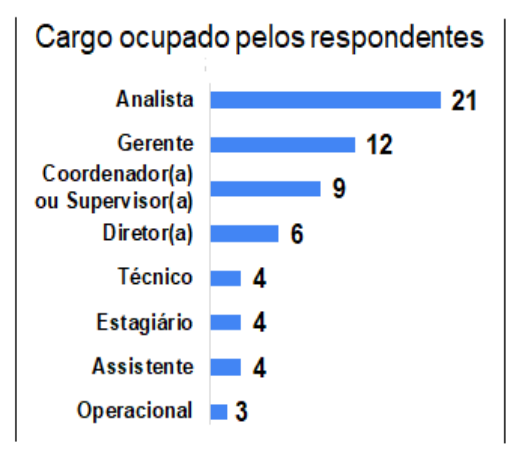

(b)

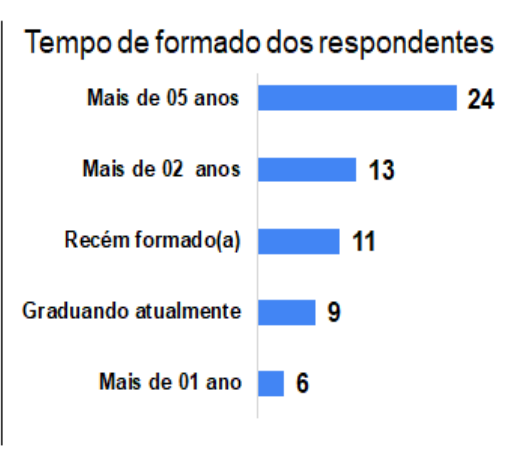

(c)

Fonte: Elaborado pelos autores (2020).

Os respondentes foram questionados quanto ao nível de conhecimento sobre a Indústria 4.0 em uma escala de 0 a 10, onde: 0 significa nenhum conhecimento e 10 muito conhecimento. Observa-se na Figura 4 que 38\% dos respondentes afirmaram possuir conhecimento de 0 a 5 e $51 \%$ com conhecimentos razoáveis de 6 a 8 . Apenas $11 \%$ dos respondentes acreditam ter bons/ótimos conhecimentos sobre a Indústria 4.0.

Figura 4 - Caracterização dos respondentes.

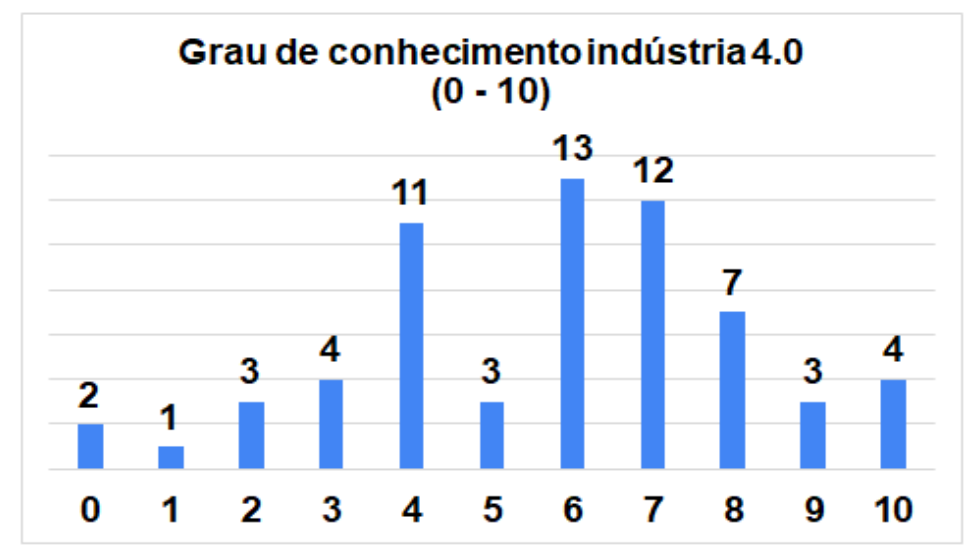

Fonte: Elaborado pelos autores (2020). 
Sobre a especialização e/ou realização de algum curso relacionado a indústria 4.0, observase na Figura 5 que apenas $25 \%$ já realizaram e $75 \%$ nunca participaram de algum curso e/ou treinamento. Logo, observa-se um potencial para a realização de treinamentos sobre a indústria 4.0, uma vez que a maioria dos respondentes possuem mais de 5 anos de formados.

Figura 5 - Realização de cursos e/ou treinamentos sobre a indústria 4.0.

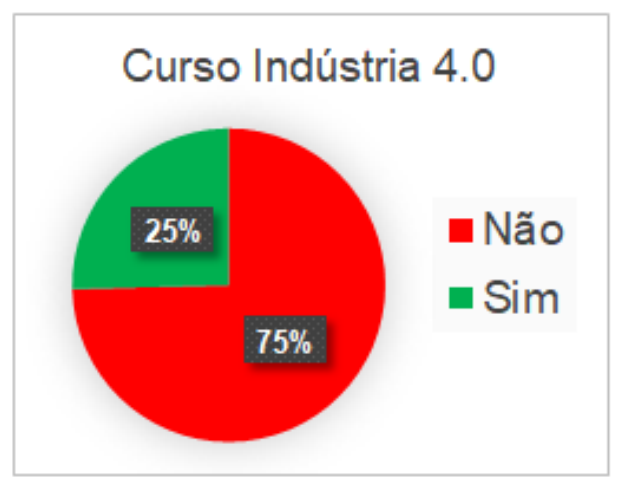

Fonte: Elaborado pelos autores (2020).

A Figura 6 ilustra o nível de interação dos respondentes com os pilares da Indústria 4.0. Exceto a computação na nuvem, para todos os demais pilares da indústria 4.0 há baixa interação com os respondentes que informaram não desenvolver nenhuma atividade relacionada.

Figura 6 - Interação dos respondentes com os pilares da indústria 4.0.

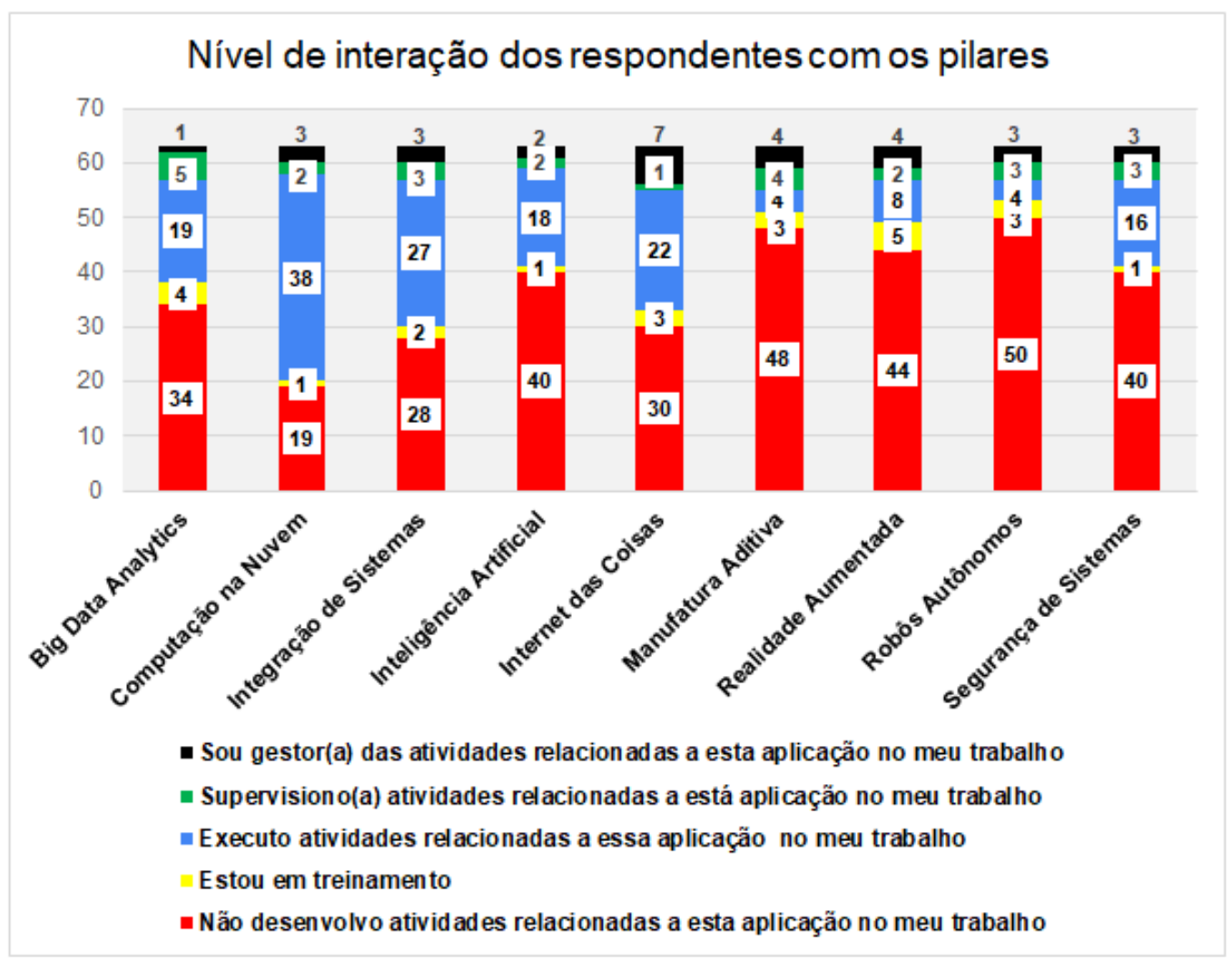

Fonte: Elaborado pelos autores (2020).

A Figura 7 ilustra a relevância dos pilares da indústria 4.0 segundo a opinião dos respondentes. Dentre os pilares mais importantes, observa-se o Big Data Analytics, Integração 
de Sistemas e Internet das Coisas. Os pilares da indústria 4.0 de menor relevância segundo os respondentes são realidade aumentada e manufatura aditiva.

Figura 7 - Relevância dos pilares.

\section{Relevância dos pilares segundo os respondentes}

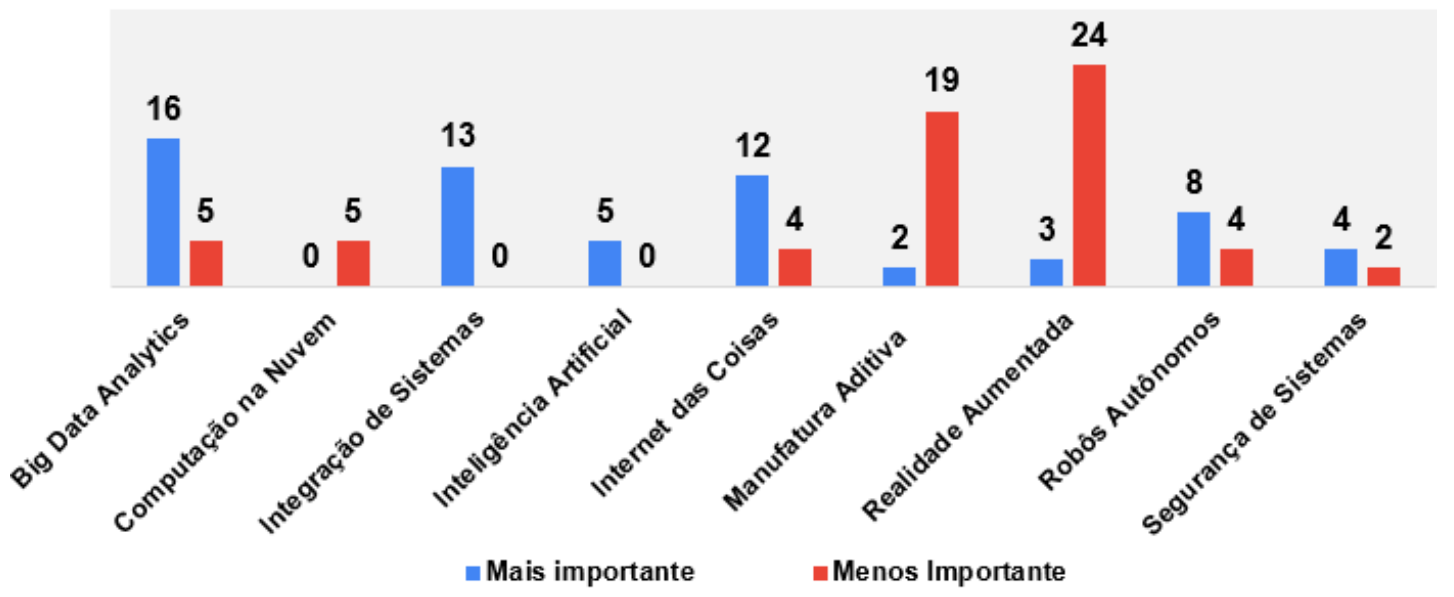

Fonte: Elaborado pelos autores (2020).

A partir dos dados apurados, sugere-se que sejam tomadas ações pelas partes interessadas para uma maior aderência dos pilares da indústria 4.0. Dentre as partes interessadas, destaca-se os governos em todas as suas esferas, a indústria e os profissionais da área.

\section{CONSIDERAÇÕES FINAIS}

Este trabalho propôs-se a analisar a aderência dos pilares da indústria 4.0 para os profissionais da Engenharia de Produção. Como resultado desta análise, observa-se que os que os pilares da indústria 4.0 que possuem maior aderência é computação na nuvem e integração de sistemas. Os demais pilares da indústria 4.0 que possuem nenhuma ou aderência parcial baixa com os profissionais de Engenharia de Produção. Dessa forma, confirma-se a hipótese mais provável de que existe baixa aderência entre os pilares da indústria 4.0 e os profissionais que atuam na área da Engenharia de Produção.

As limitações para a realização desta pesquisa apresentam-se com relação a baixa prédisposição dos respondentes em colaborar a realização deste trabalho.

Por se tratar de um tema relevante, também é esperado que este trabalho possa motivar novos docentes e discentes de diferentes instituições de ensino e cursos a monitorarem a aderência dos pilares da indústria 4.0 em suas áreas de atuação.

Sugere-se para a realização de trabalhos futuros, explorar os pilares da indústria $4.0 \mathrm{com}$ baixa e/ou nenhuma aderência com os profissionais que atuam na área da Engenharia de Produção.

\section{Agradecimentos}

Os agradecimentos à Instituição de Ensino Superior pelo apoio e incentivo a pesquisa, seu corpo docente, administração e coordenação. Os agradecimentos aos colegas que colaboraram direta ou indiretamente com a realização deste trabalho. 


\section{REFERÊNCIAS}

BATALHA, M. Introdução a Engenharia de Produção. 3ª ed. Rio de Janeiro. 2008.

BOETTCHER, M. Revolução Industrial -Um pouco de história da Indústria 1.0 até a Indústria 4.0. Linkedin. 26 nov. 2015. Disponível em: <https://pt.linkedin.com/pulse/revolu\%C3\%A7\%C3\%A3o-industrial-um-pouco-de-hist\%C3\%B3ria-da10-at\%C3\%A9-boettcher>. Acesso em: 05 maio 2020.

CNI. Confederação Nacional da Indústria. Disponível em: <http://www.portaldaindustria.com.br> Acesso em: 22 mai. 2020.

COSTA, Cesar da. Indústria 4.0: o futuro da indústria nacional. Pós-Graduação em Revista, São Paulo, v. 1, n. 4, p. 5-14, 2017. Disponível em: <http:// seer.spo.ifsp.edu.br/index.php/posgere/article/download>Acesso em: 22 mai. 2020.

CUNHA, G. D. Um panorama atual da Engenharia da Produção no Brasil. Porto Alegre: [s.n.], 2002.

CUNHA, Luísa Margarida Antunes da et al. Modelos Rasch e Escalas de Likert e Thurstone na medição de atitudes. 2007.

FORZA, Cipriano. Survey research in operations management: a process-based perspective. International journal of operations \& production management, v. 22, n. 2, p. 152-194, 2002.

FRANZINI FILHO, Carlos Roberto et al. Análise das competências para a formação do Engenheiro de Produção e suas áreas de atuação profissional. In XIV Encontro Mineiro de Engenharia de Produção (EMEP), 2018, Juiz de Fora-MG. Anais. Minas Gerais, 2018.

Disponível em: <http://site.emepro.org/wp/2018/9-artigos-anais >. Acesso em: 22 mai. 2020.

HAHN, Rizzo. J. A Era da Internet Industrial e a Indústria 4.0 já estão moldando o futuro de muitos empreendedores. Saiba como aproveitar essa nova tendência. 2016. Disponível em: $<$ https://endeavor.org.br/uncategorized/oportunidades-industria-4_0/>Acesso em: 20 mai. 2020.

OLIVEIRA, V. F.; BARBOSA C. S. e CHRISPIM E. M. Cursos de Engenharia de Produção no Brasil: crescimento e projeções. In: XXV Encontro Nacional de Engenharia de Produção, 2005, Porto Alegre. Anais. Porto Alegre, 2005.

SACOMANO, J. B. et al. Indústria 4.0 Conceitos e Fundamentos. São Paulo: Blucher, 2018.

SAKURAI, R.; ZUCHI, J. D. AS REVOLUÇÕES INDUSTRIAIS ATÉ A INDUSTRIA 4.0. Revista Interface Tecnológica, [S. 1.], v. 15, n. 2, p. 480-491, 2018. Disponível em: https://revista.fatectq.edu.br/index.php/interfacetecnologica/article/view/386>. Acesso em: 5 jul. 2020. 
SILVA, D. O engenheiro que as empresas querem hoje. In LINSINGEN, I. von et al. Formação do engenheiro. Florianópolis: EDUFSC, 1999. cap 5, p. 77-88.

SILVEIRA, C. B. O que é a Indústria 4.0 e como ela vai impactar o mundo. Citisystems. 2017. Disponível em: $<$ https://www.citisystems.com.br/industria-4-0/>. Acesso em: 20 mai. 2020.

SURVEY MONKEY. Calculadora de tamanho de amostra 2020. Disponível em: $<$ https://pt.surveymonkey.com/mp/sample-size-calculator/>.Acesso em: 25 jul. 2020.

VENTURELLI, M. Indústria 4.0: uma visão da automação industrial. Automação Industrial, nov. 2017. Disponível em:<https://www.automacaoindustrial.info/industria-4-0-umavisao-da-automacao-industrial/>. Acesso em: 10 mai. 2020.

\title{
ANALYSIS OF ADHERENCE BETWEEN INDUSTRY 4.0 PILLARS AND PRODUCTION ENGINEERING PROFESSIONALS
}

\begin{abstract}
The Engineering Production professionals are able to work with several areas organization and they can be responsible about materials management, financial and human resources. If a production engineering professional wants to build a successful career in Engineering, it is very important take a look at some factors like professional updating. So, the industry 4.0 (Fourth Industrial Revolution) is a recent concept about technological innovations applied on manufacturing and services processes. Therefore, the aims from this work is to analyze the adherence between industry 4.0 pillars and Production Engineering professionals. In order to achieve the proposed objective, it was applied an exploratory survey on Production Engineering professionals. The results pointed to the pillars from industry 4.0 with greater and lesser adherence on Production Engineering professionals. It is hoped the achieved results by this work can contribute motivating future works about industry 4.0 pillars.

It is suggested to deepen the studies about industry 4.0 pillars industry with less adherence.
\end{abstract}

Keywords: Production Engineering, Industry 4.0, Fourfh Industrial Revolution. 